\title{
Accessibility of Radio Frequency Identification Technology in Facilities Maintenance
}

\author{
Chien-Ho Ko \\ Professor, Department of Civil Engineering, National Pingtung University of Science and Technology, 1, Shuefu Rd., \\ Neipu, Pingtung 912, Taiwan. E-mail: ko@mail.npust.edu.tw
}

Engineering and Project Management

Received December 16, 2016; received revision January 13, 2017; accepted January 18, 2017

Available online January 19, 2017

\begin{abstract}
Replacing old buildings with new structures is an expensive proposition, but the service life of existing buildings can be extended by improving facilities maintenance. In particular, effective use of information technology can improve facilities maintenance and reduce maintenance costs. In recent years, some scholars have begun to apply Radio Frequency Identification (RFID) technology to facilities maintenance. The present study examines the effective reading range for RFID applications within the context of facilities maintenance, where such applications can provide advantages including automatic reading and encoding of equipment, rapid reading and encoding of tag information, and tag-based data storage. However, the reading range of RFID tags can be limited by the presence of water vapor, electrical appliances, and metal surfaces. Through practical onsite testing, the study examines how effective reading range is impacted by dust, water, metal surfaces and electrical equipment, along with various reading and writing angles. Experimental results show that the presence of dust and water both have insignificant impacts on RFID signal reading. However, metal surfaces were found to have a significant negative effect on signal reading and RFID tags should be kept an appropriate distance from such materials. The results of this study can be taken as reference for the use of RFID in facilities maintenance and management.
\end{abstract}

Keywords: Facilities maintenance, facilities management, RFID technology, accessibility range.

\section{Introduction}

Building density continues to increase in urban areas, increasing demand demolishing old structures to free up land for new construction. However, the service livespan of older buildings can be effectively prolonged by enhancing facilities maintenance (Barco, 1994; Djerdjouri, 2005). Radio Frequency Identification (RFID) technology uses integrated circuits (ICs) and radio waves to store and transmit identification data. RFID devices are environmentally durable, allow multiple reading and writing operations, operate without direct contact, can record a wide variety of data, and can read multiple tags within a set range (Fontelera, 2005).

Several attemps have been made to apply RFID to facilities maintenance and management (Ko, 2010; Ko, 2013). Yokota (2017) presented a framework for the life-cycle management system for shore facility protection, introducing methodologies for practical maintenance. Leung et al. (2016) attempted to improve indoor facilities for public housing for the elderly, using a post-occupancy evaluation questionnaire to investigate the relationship between indoor facilities management and resident quality of life. Wei et al. (2016) presented an IoT-based communication framework to develop an energy management system for industrial facilities, integrating information technologies to enhance the efficiency of facilities management (Yalcinkaya and Singh, 2014; Ahn, 2016; Hu et al., 2016). Motamedi et al. (2014) used the Building Information Modeling (BIM) to create useful visualizations for facilities management technicians (Becerik-Gerber et al, 2012; Mignard and Nicolle, 2014).

Legner and Thiesse (2006) applied RFID technology to the maintenance of facilities in Frankfurt Airport in Germany. Results of their study showed that facility management plans and controls, along with administrative recordkeeping by technical staff could be improved by the use of RFID technology, thus creating a smoother flow of maintenance work (Legner and Thiesse, 2006). Ergen et al. 
(2007) used RFID technology to address difficulties in traditional facilities maintenance, such as slow data transmission, long processing times, and difficulty in establishing maintenance history.

Motamedi et al. (2011) used RFID tags as permanent repositories of component-specific information, allowing stakeholders (e.g., architects, engineers, construction crews, owners, and operators) to share information. In addition, cost and labor required to add and remove tags could be eliminated during the lifecycle by reducing data storage duplication among different stakeholders. RFID has further been applied to tracking and allocating assets for facilities maintenance (Motamedi et al., 2013; Zalzala et al., 2015; Ko 2010). For example, Ko (2013) used RFID technology with computational algorithms to estimate component positions in indoor areas based on received signal strength.

RFID technologies can thus be used to improve current facitilies maintenance operations and procedures, reducing the need for management personnel, lowering total management costs, reducing repetitive paperwork, and accelerating maintenance management processes.

The use of BIM and RFID has been investigated for facilities maintenance in venues including riverbanks, public housing, and industrial facilities. The first challenge of using RFID for facility maintenance is ensuring the effective reading of on-site electronic tags. RFID systems transmit information using radio waves, thus effective readability can be compromised by a variety of environ,mental factors including water vapor, electrical appliances, and metal surfaces. However, few previous studies have taken such limitations into account.

The purpose of this study is to determine the effective reading range of RFID systems deployed for facility maintenance. Onsite testing in authentic facilities allows the results to serve as a valuable reference for RFID applications for facility maintenance.

The remainder of this paper is organized as follows. Section 2 provides a brief overview of RFID technologies, including the principle of operation, system architecture, and application challenges. Section 3 compares advantages and disadvantages of barcode and RFID approaches. Section 4 describes tests in authentic facilities to determine the effective read range of RFID tags. Section 5 presents conclusions.

\section{RFID Technology}

RFID is a type of non-contact automatic identification system consisting of a tag and a reader which transmit identification data using radio waves. Passive RFID tags include an integrated circuit and a simple antenna, and do not require a battery. The reader intermittently emits energy, providing the tag with sufficient energy to return data to the reader.

In 1977, the Los Alamos National Laboratory began to develop non-contact technologies and tried to implant primitive RFID tags into livestock for tracking purposes. In the early 1980s, relevant technologies were successfully miniaturized to the point where tags could be embedded in employee ID cards to replace the use of traditional keys, thus enhancing convenience and security (Su, 2005).
In 1989, Texas Instruments developed Texas Instruments Registration and Identification Systems (TIRIS), which led to a significant and continuous decline in component costs, thus driving a rapid expansion of applications. Today, RF products are ubiquitous in applications such as stored value cards, chip keys for motor vehicles, access control systems, anti-theft merchandise tags, automated production lines, materials management, chip implants in pets, and highway toll systems

RFID systems consist of three major components - the tag, the reader, and the application system:

1. Electronic tag: As shown in Fig. 1, RFID tags can be divided into active and passive types, where passive tags do not require a battery to function.

- Active tags: An active tag has a battery and a wake-up device to rouse it from its default dormant state. When a tag comes within sensing range of the wake-up device, the tag is activated by radio waves or electromagnetic fields, and begins transmitting information to the reader. Battery-powered active tags have considerably greater transmission ranges, typically from $30 \mathrm{~m}$ to $100 \mathrm{~m}$. However, such devices are typically larger in size, cost more to manufacture, and will fail if the battery dies.

- Passive tags: A passive tag converts energy received from the reader into electrical power to operate its integrated ciruit, thus obviating the need for a battery or other power source. This provides advantages including small size, low cost, long service life, and digital data portability. Currently, the Ultra High Frequency (UHF) tag enables for the furthest sensing distance among passive tags, reaching $5 \mathrm{~m}$ to $7 \mathrm{~m}$ at places with fewer sources of interference (Finkenzeller, 2010).

2. Reader/writer: Using high frequency electromagnetic waves to transmit energy and signals, an RFID reader/writer can identify over 50 electronic tags per second. Fig. 2 shows examples of actual RFID $\mathrm{read} /$ write devices.

3. Application system: An RFID application system incorporates database management, computer networking and firewall applications, functioning as a fully-automatic, safe, and convenient real-time monitoring system. A prototypical RFID sytem is illustrated in Fig. 3 (Chiou, 2006).

Presently, RFID technology has yet to overcome the following difficulties:

1. Metal and water in the sensing environment can cause a certain degree of interference. Interference caused by metal surfaces can be countered through the use of expensive absorbing materials, but inference caused by water is much more troublesome. Water interference can result from liquid water contained in the tagged object, by high environmental humidity or even the movement of the personnel (as $70 \%$ of a human body is water). System interference from water increases with system frequency. 
2. Data can't be read when tags overlap.

3. Overlapping read/write device alignment can cause reading problems.

4. High manufacturing costs and discrepancies between UHF band allocation in different countries.

\section{Comparison of RFID and Barcode}
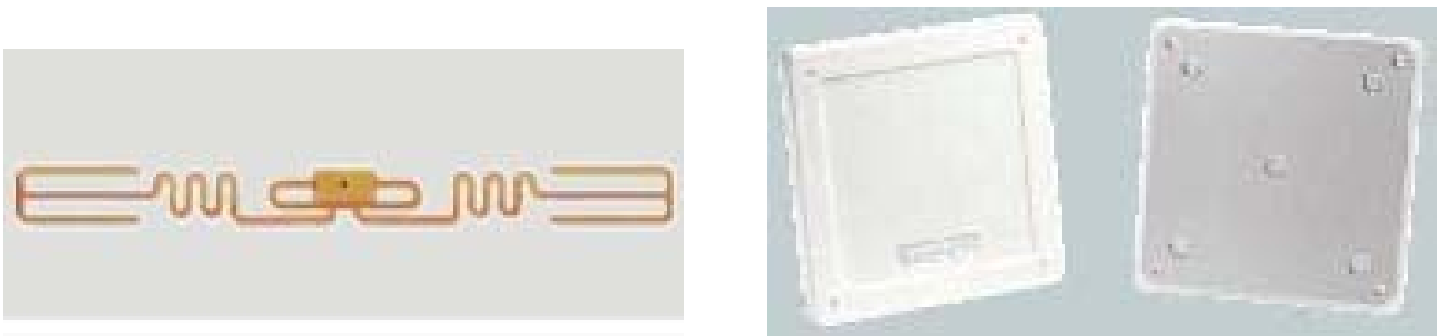

Fig. 1. Electronic tags
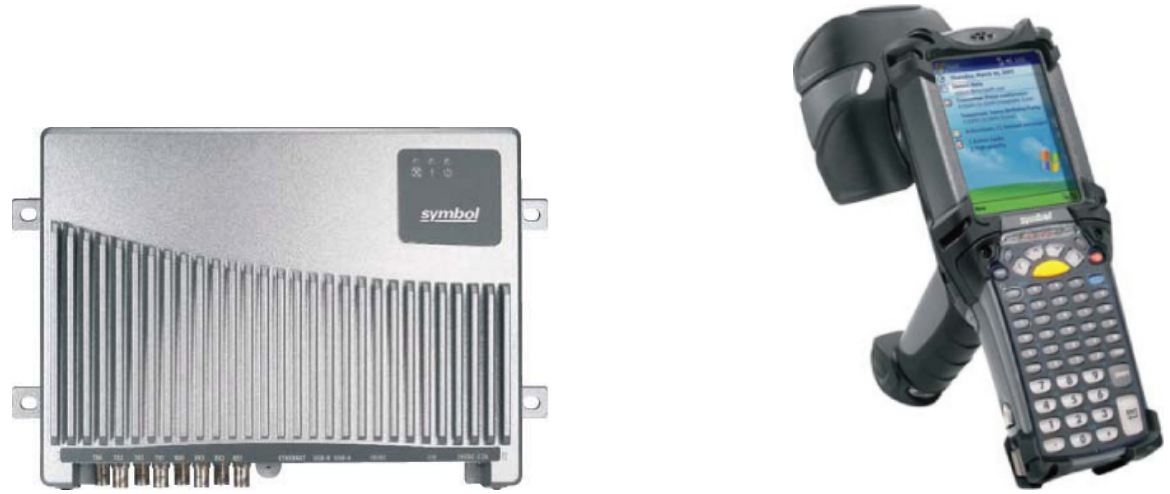

Fig. 2. RFID reader/writer

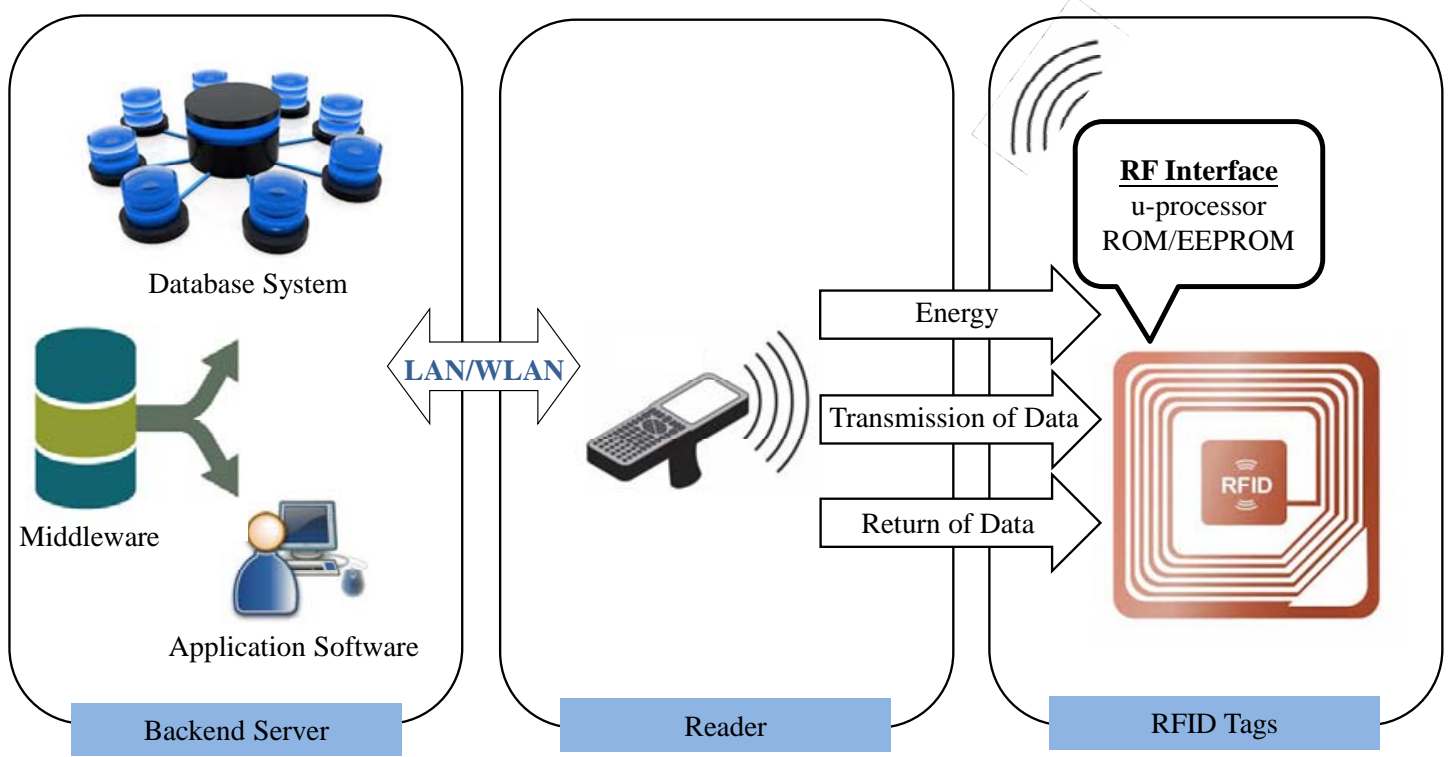

Fig. 3. Prototypical RFID system 
Table 1. Comparison of RFID and barcodes

\begin{tabular}{|c|c|c|}
\hline Item & Barcode & RFID \\
\hline Data transmission method & Optical & Electromagnetic \\
\hline Data storage capacity & 1-100 bytes & 128-8K bytes \\
\hline Data revisability & Not revisable & Revisable \\
\hline Contact & Physical contact required & $\begin{array}{c}\text { No contact required } \\
\text { (line of sight not required) }\end{array}$ \\
\hline Read range & Within a few meters in linear distance & A few centimeters to few kilometers \\
\hline Environmental sensitivity & Line of sight required & $\begin{array}{l}\text { Easily affected by water vapor and } \\
\text { electrical appliances }\end{array}$ \\
\hline Reading speed & Slow & Very fast (over 50 tags per second) \\
\hline Reading capacity & One at a time & Multiple simultaneous reads \\
\hline Durability & Easily damaged & Maximum 20 years \\
\hline Tracking & Incapable of tracking and positioning & Capable of tracking and positioning \\
\hline
\end{tabular}

\section{RFID Accessibility Experiments}

\subsection{RFID Reader/Writer}

The Ensyc RFID Block (see Fig. 4) was selected based on its small unit size and weight, long effective reading range, high interface usability, low price, wide frequency band and wide adoption. The Ensync RFID block is a stand alone RFID reader specially designed for use with PCs and tablets via USB connector. This low power device uses an RF 1200 reader printed circuit board. The user interface was modified using the Ensync SDK. Via UHF, the RFID Block can read both Class 1 Gen 1 and Gen 2 RFID tags. Detailed specifications of the used RFID reader are listed in Table 2.

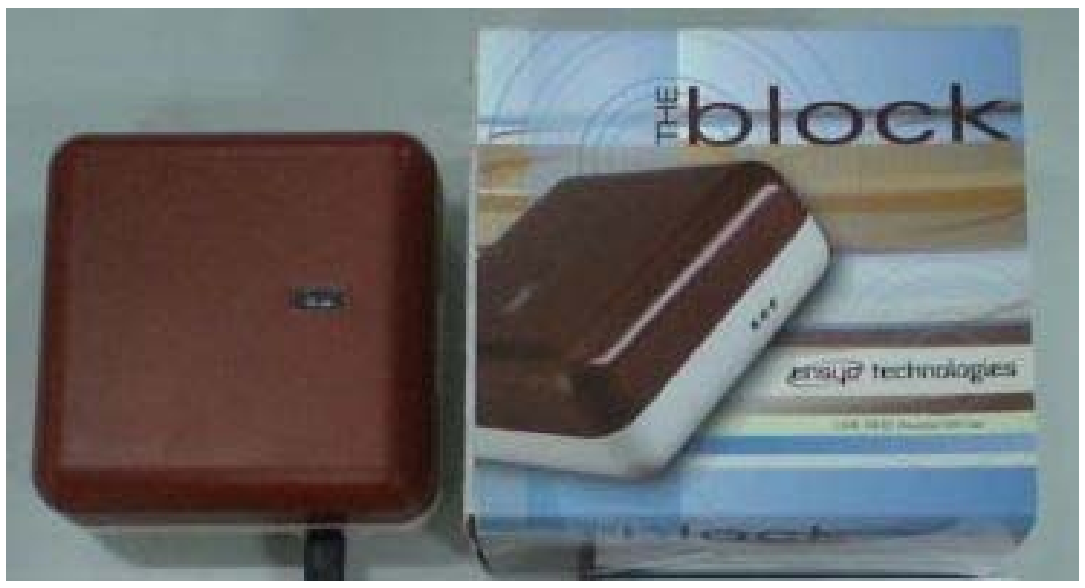

Fig. 4. Ensync RFID reader

Table 2. Ensyc RFID Block Specifications

\begin{tabular}{cc}
\hline Item & Specifications \\
\hline Operating frequency & 860 960 MHz (UHF) \\
Communication format & EPC C0/0+/1/1Gen2, ISO 18000 6C \\
Communication interface & USB \\
Operating system & Not limited \\
Volume size & $114.3 X 114.3 X 50.8 \mathrm{~mm}$ \\
Development software & Visual Studio.NET
\end{tabular}




\subsection{Experiments and Results}

RFID read range is susceptible to interference from the presence of water vapor, electrical appliances and metal surfaces. In addition, the angle of exposure between the tag and the reader would also affect the effective range. To assess reading effectiveness, experiments were conducted with varying degrees of environmental water, different exposure angles, and with placement of electronic appliances and metal surfaces at varying distances to the RFID tag. As shown in Fig. 5, the antenna of the Gen 2 RFID tag used in the study measured $9.49 \mathrm{~cm}$ $\mathrm{x} 0.79 \mathrm{~cm}$, and the device is attached using an adhesive. Detailed specifications are shown in Table 3.

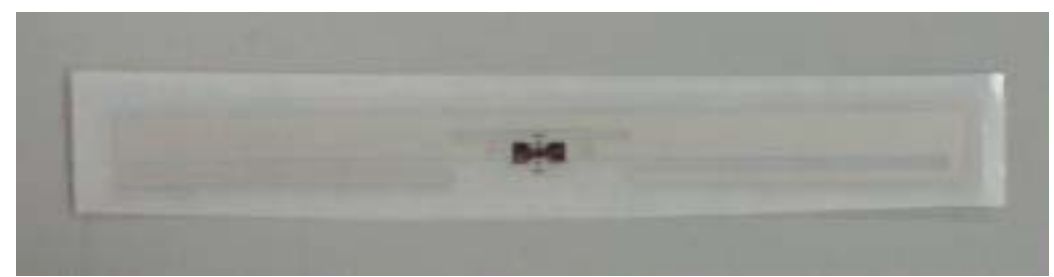

Fig. 5. Gen 2 RFID tag used in the study (enlarged for details)

Table 3. Specifications of the avery dennison AD-222 RFID tag

\begin{tabular}{cc}
\hline Item & Specifications \\
\hline Operating frequency & $860 \sim 960 \mathrm{MHz}$ (UHF) \\
Mode of operation & Passive \\
Communication format & EPC C0/0+/1/1Gen2, ISO $180006 \mathrm{C}$ \\
Tag length & 96 Bits \\
Operating temperature & $-40^{\circ} \mathrm{C}$ to $+65^{\circ} \mathrm{C}$ \\
Operating humidity & $40 \%$ to $80 \% \mathrm{RH}$ \\
\hline
\end{tabular}

\section{Testing under General Conditions}

First, we tested effective reading range under general conditions to establish a standard distance for tag reading without interference. In the experiment, the RFID tag was placed directly above the reader, at varying distances, as illustrated in Fig. 6. Each distance was tested five times, with results summarized in Table 4 . The effective maximum range was found ot be approximately $10 \mathrm{~cm}$.

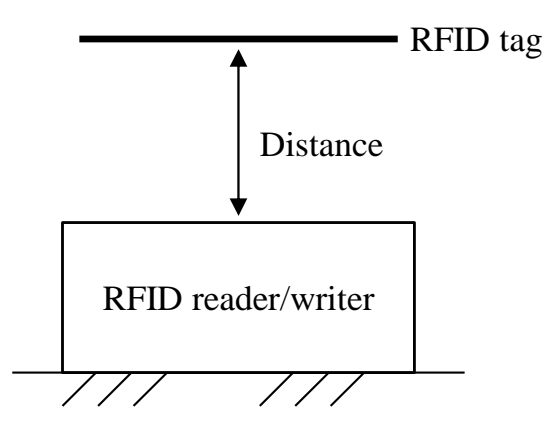

Fig. 6. Experiments under general conditions

Table 4. Effective ranges under general conditions

\begin{tabular}{ccc}
\hline Distance $(\mathrm{cm})$ & No. of Successes & No. of Failures \\
\hline 5 & 5 & 0 \\
6 & 5 & 0 \\
7 & 5 & 0 \\
8 & 5 & 0 \\
9 & 5 & 0 \\
10 & 5 & 5 \\
11 & 0 & 5 \\
\hline
\end{tabular}




\section{Dust Test}

To determine whether the long-term accumulation of dust would impact RFID signal reading performance, a dust experiment was performed as illustrated in Fig. 7. Dust was spread to evenly cover the entire tag. As shown in Table 5, the presence of dust only slightly reduced the effective read range to $9 \mathrm{~cm}$.

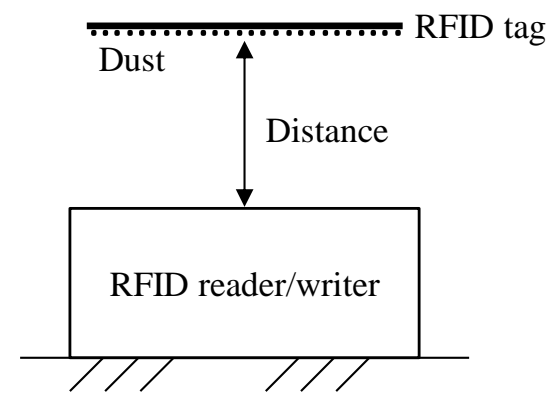

Fig. 7. Dust experiment
Water absorbs UHF waves, thus reducing effective RFID reading range. In practice, water droplets may cover the tag surface, or water vapor may be dispersed in the atmosphere. Water droplets were evenly-distributed on a tag, as illustrated in Fig. 8, with the tag separated from the reader at a distance of $9 \mathrm{~cm}$. As shown in Table 6, the read range was not reduced by the presence of water droplets.

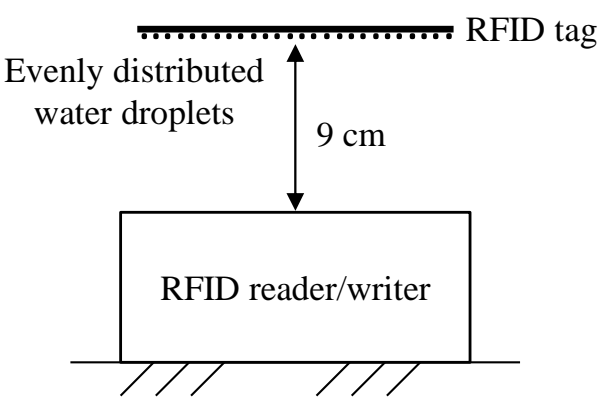

Fig. 8. Water experiment

Table 5. Dust experiment results

\begin{tabular}{ccc}
\hline Distance $(\mathrm{cm})$ & No. of Successes & No. of Failures \\
\hline 5 & 5 & 0 \\
6 & 5 & 0 \\
7 & 5 & 0 \\
8 & 5 & 0 \\
9 & 5 & 5 \\
\hline
\end{tabular}

Table 6. Results of the water experiment

\begin{tabular}{ccc}
\hline Waterdroplets (ml) & No. of Successes & No. of Failures \\
\hline 2 & 5 & 0 \\
4 & 5 & 0 \\
6 & 5 & 0 \\
8 & 5 & 0 \\
10 & 5 & 0 \\
12 & 5 & 0 \\
\hline
\end{tabular}

\section{Metal Test}

Some equipment has metallic outer casings which can reflect radio waves, interfering with the RFID read range. As illustrated in Fig. 9, an RFID tag was positioned $9 \mathrm{~cm}$ from the reader, and a metal plate was placed at varying distance to the tag. As shown in Table 7, results indicated that direct contact between the RFID tag and the metal surface blocked tag reading, but this limitation gradually reduced as the metal plate was withdrawn from the tag, with reliable readings achieved at a distance of $2 \mathrm{~cm}$. 


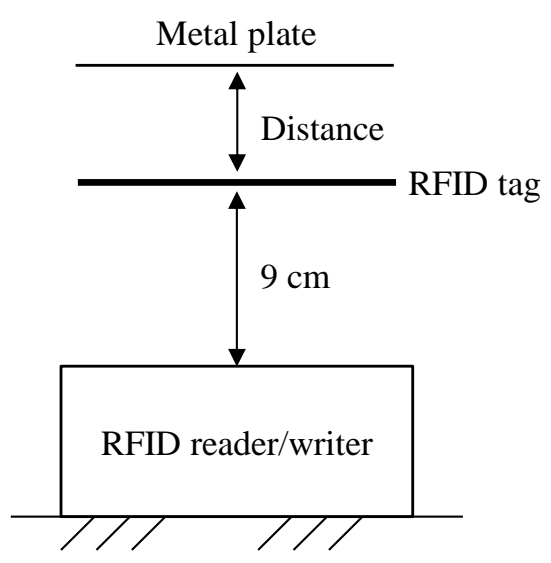

Fig. 9. Metal experiment

\section{Electronic Appliance Test}

Practical facilities typically house a range of electrical appliances, including computers and electronic instruments. As shown in Fig. 10, the RFID tag was placed $9 \mathrm{~cm}$ away from the reader, while an operating PC was positioned at varying distances from the tag. Results shown in Table 8 indicate showed that the RFID tag should not be placed at least $3 \mathrm{~cm}$ from such electronic equipment to ensure normal signal reading.

\section{Angle Test}

In practice it is difficult to control the angle of exposure between the RFID reader and the tag. To determine whether this angle will affect the RFID reading range, an experiment was designed as shown in Fig. 11. From an initial angle of zero degrees, the angle of exposure was increased in 30 degree increments to 180 degrees (i.e., the rear far of the tag faces the reader). As shown in Table 9, results suggest the angle of exposure has a negligible effect on reading performance.

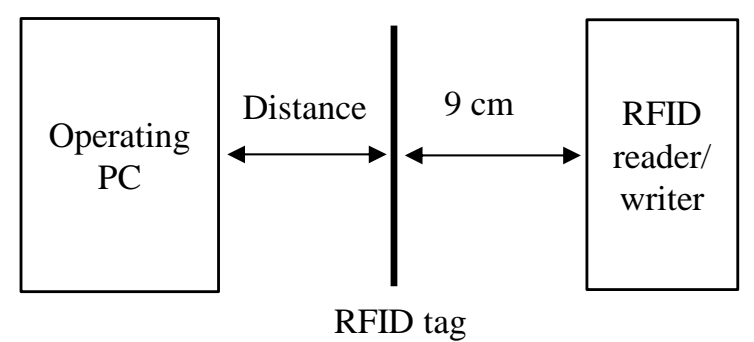

Fig. 10. Electronic equipment experiment

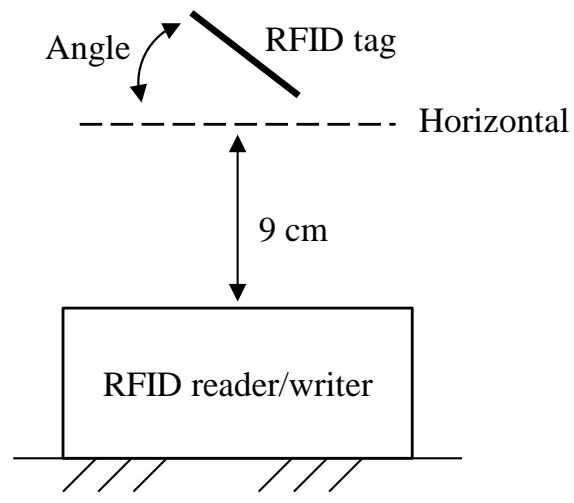

Fig. 11. Angle experiment

Table 7. Metal experiment results

\begin{tabular}{ccc}
\hline Distance $(\mathrm{cm})$ & No. of Successes & No. of Failures \\
\hline 0 & 0 & 5 \\
1 & 3 & 2 \\
2 & 5 & 0 \\
3 & 5 & 0 \\
\hline
\end{tabular}

Table 8. Electronic equipment experiment results

\begin{tabular}{ccc}
\hline Distance $(\mathrm{cm})$ & No. of Successes & No. of Failures \\
\hline 0 & 0 & 5 \\
1 & 0 & 5 \\
2 & 0 & 0 \\
3 & 5 & 0 \\
4 & 5 & 0 \\
\hline
\end{tabular}


Table 9. Angle experiment results

\begin{tabular}{ccc}
\hline Angle (degree) & No. of Successes & No. of Failures \\
\hline 0 & 5 & 0 \\
30 & 5 & 0 \\
60 & 5 & 0 \\
90 & 5 & 0 \\
120 & 5 & 0 \\
150 & 5 & 0 \\
180 & 5 & 0 \\
\hline
\end{tabular}

\section{Conclusions}

RFID technologies provide advantages that can greatly reduce the time and manpower needed for facilities maintenance and for tracking and monitoring equipment. Using authentic test conditions, this study measured the effective read range of the RFID tag in real facilities to determine the impact of dust, water, metal surfaces, electronic equipment and various exposure angles. Experimental results showed that the distance between the tag and the reader was a critical factor to ensure successful RFID signal reading. In addition, proximity to metallic surfaces was found to influence reading performance, while the presence of water droplets and dust particles had no significant impact, nor did the exposure angle. RFID tags should be placed at least $2 \mathrm{~cm}$ away from metal surfaces, and at leat $3 \mathrm{~cm}$ from operating electronic equipment. These results can serve as a useful reference for the application of RFID technologies for facilities maintenance.

\section{Acknowledgements}

The author would like to thank the graduate student, Yi-He Lai, who helped carry out experiments. This research was funded by the Architecture and Building Research Institute (Taiwan).

\section{References}

Ahn, B. T. (2016). Implementation of digital contents system for cleaning facility management based on Bluetooth. International Journal of Smart Home, 10(7), 259-268.

Barco, A.L. (1994). Budgeting for facility repair and maintenance. Journal of Management in Engineering, 10(4) 28-34.

Becerik-Gerber, B., Jazizadeh, F., Li, N., Calis, G. (2012). Application areas and data requirements for BIM-enabled facilities management. Journal of Construction Engineering and Management, 138(3), 431-442.

Chan, H. L., Choi, T. M., Hui, C. L. (2012). RFID versus bar-coding systems: Transactions errors in health care apparel inventory control. Decision Support Systems, 54(1), 803-811.

Chiou, Y. T. (2006). The development of a "from vessel to table" traceability system of bluefin tuna for a
Japanese restaurant. Master Thesis, National Taiwan Ocean University.

Djerdjouri, M. (2005). Assessing and benchmarking maintenance performance in a manufacturing facility: A data envelopment analysis approach. INFOR, 43(2) 121-133.

Ergen, E., Akinci, B., East, B., and Kirby, J. (2007). Tracking components and maintenance history within a facility utilizing radio frequency identification technology. Journal of Computing in Civil Engineering, 21(1), 11-20.

Finkenzeller, K. (2010). RFID Handbook: Fundamentals and Applications in Contactless Smart Cards, Radio Frequency Identification and Near-Field Communication. Wiley, West Sussex, UK.

Fontelera, J. (2005). RFID exploration. Converting Magazine, 23(9) 28-32.

Hu, Z. Z., Zhang, J. P., Yu, F. Q., Tian, P. L., Xiang, X. S. (2016). Construction and facility management of large MEP projects using a multi-Scale building information model. Advances in Engineering Software, 100, 215-230.

Hunt, V.D., Puglia, A., and Puglia, M. (2007).RFID-A Guide to Radio Frequency Identification. Wiley-Interscience.

Ko, C. H. (2010). RFID 3D location sensing algorithms. Automation in Construction, 19(5), 588-595.

Ko, C. H. (2013). 3D-Web-GIS RFID Location Sensing System for Construction Objects. The Scientific World Journal, 2013, Article ID 217972.

Lee, Y. C. (2005). System Analysis and Planning for RFID Application in Medical Institutes. Master Thesis, National Chung Cheng University (in Chinese).

Legner and Thiesse (2006). RFID-based maintenance at Frankfurt airport. IEEE Pervasive Computing, 5(1), 34-39.

Leung, M.Y., Yu, J., Memari, A. (2016). Managing indoor facilities in public housing to improve elderly quality of life. International Journal for Housing Science and Its Applications, 40(2), 85-98.

Mignard, C. and Nicolle, C. (2014). Merging BIM and GIS using ontologies application to Urban facility management in ACTIVe3D. Computers in Industry, 65(9), 1276-1290. 
Motamedi, A., Saini, R., Hammad, A., Zhu, B. (2011). Role-based access to facilities lifecycle information on RFID tags. Advanced Engineering Informatics, 25 (3), 559-568.

Motamedi, A., Soltani, M. M., Hammad, A. (2013). Localization of RFID-equipped assets during the operation phase of facilities. Advanced Engineering Informatics, 27(4), 566-579.

Motamedi, A., Hammad, A., Asen, Y. (2014). Knowledge-assisted BIM-based visual analytics for failure root cause detection in facilities management. Automation in Construction, 43, 73-83.

Su, Y. S. (2005). Radio Frequency Identification (RFID) Network for Controlled Drug Management Prototype System. Master Thesis, National Chung Kung University (in Chinese).

Talavera, H. E., Banks, J., Smith, N. R., Cárdenas-Barrón, L. E. (2015). Enhancing the management of shared inventory in the steel industry using RFID: an alternative to bar codes. International Journal of Machine Learning and Cybernetics, 6(5), 733-745.

Wei, M., Hong, S. H., Alam, M. (2016). An IoT-based energy-management platform for industrial facilities. Applied Energy, 164, 607-619.

Wesi, S.A., SarmaS.E. Rivest, R.L., (2003). Security and privacy aspects of low-cost radio identification systems. International Conference on Security in Pervasive Computing, 2802, 454-469.

Yalcinkaya, M., Singh, V. (2014). Building information modeling (BIM) for facilities management-literature review and future needs. IFIP Advances in Information and Communication Technology, 442, 1-10.

Yokota (2017). Practical application of life-cycle management system for shore protection facilities. Structure and Infrastructure Engineering, 13(1), 34-43.

Zalzala, A., Strettle, V., Chia, S., Zalzala, L., (2015). RFID individual tracking and records management: Solutions for slum communities. IEEE Technology and Society Magazine, 34(1), 45-55.

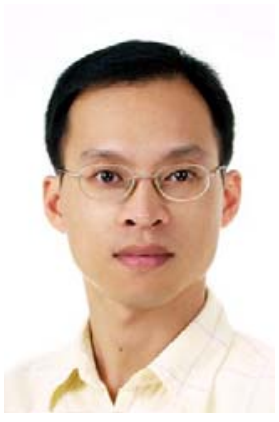

Dr. Chien-Ho Ko is currently a full professor in the Civil Engineering Department at National Pingtung University of Science and Technology. He was a faculty member in the Industrial Engineering and Technology Management Department at Da-Yeh University. Prior to this profession, Dr. Ko conducted his postdoctoral research at the University of California at Berkeley on government funds of Ministry of Education. He is a registered professional engineer of fire protection. His research encompasses around lean construction, robotics, artificial intelligence, and information technology. 